\title{
L-Serine from D-Glucosamine
}

By

\author{
Koh-Iti Turumi and Sakae Yamada \\ (鶴見 “琴 $\rightarrow$ ) (山田筞) \\ From the Department of Biochemistry, Fukushima \\ Medical College, Fukushima \\ (Received for publication, October 10, 1954)
}

Wolfrom, Lemieux and Olin ${ }^{1)}$ confirmed the 2-amino group in the molecule of D-glucosamine to have the same relative configuration as the $2-\mathrm{OH}$ in $\mathrm{D}$-glucose, by deriving $\mathrm{L}$-alanine from the amino sugar. If then, L-serine should be obtained by the procedure following:

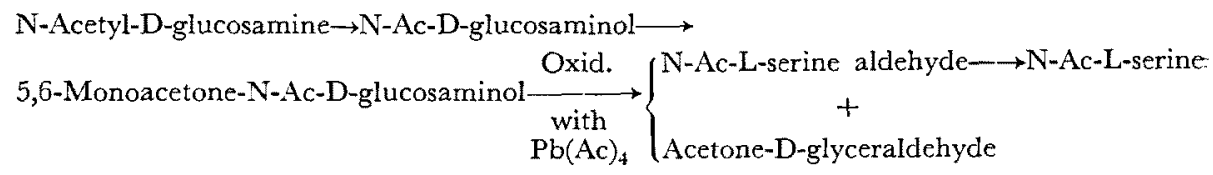

Actually we could thus obtain L-serine from D-glucosamine.

\section{EXPERIMENTAL}

N-Acetyl-D-glucosamine was synthesized by the method of ZuckerkandI and Messiner-Klebermass ${ }^{2}$.

Reduction of $\mathcal{N}$-acetyl-D-glucosamine. Karrer \& Meyer $^{3 \prime}$ have obtained $\mathrm{N}$-Ac-D-glucosaminol by reduction of $\mathrm{N}$-Ac-D-glucosamine with nickel catalyst under high temperature and pressure. We used aluminium amalgam as a reducing agent according to Nanji and Paton procedure ${ }^{4}$. Namely, $2 \mathrm{~g}$. of N-Ac-D-glucosamine was dissolved in $16 \mathrm{ml}$. of distilled water, $3 \mathrm{~g}$. of aluminium amalgam were added to the solution, and then the $\mathrm{pH}$ of the solution was adjusted to 7.8 by adding 5 per cent ammonium hydroxide. Reduction was processed at the temperature of $37-38^{\circ} \mathrm{C}$. After 36 hours the solution gave no Fehling's reaction. The solution was filtered off from the precipitate and the filtrate and the washings were concentrated to a syrup under reduced pressure after slightly acidifying with $1 N$ hydrochloric acid to $\mathrm{pH} 6.2$. Next, to the syrup was added about $30 \mathrm{ml}$. of methanol-ether mixture $(1: 3)$ until turbidity occurred and allowed to stand in an ice box overnight. Crystals appeared in thin needles with silky luster which were recrystallized from ethanol. Yield 90 per cent of theory. m.p. $156.2^{\circ}$ (uncorrected) (Karrer and Meyer") reported 
m.p. of $153^{\circ} \mathrm{C}$.). N, (Micro-Kjeldahl) $6.19 \%$ (Calc. $6.28 \%$ ).

Synthesis of 5,6-monoacetone- $\mathcal{N}$-acetyl-D-glucosaminol. $1.5 \mathrm{~g}$. of N-Ac-Dglucosaminol were shaken in anhydrous acetone with fused anhydrous zinc chloride for two hours at room temperature. To the filtrate were added $15 \mathrm{~g}$. of anhydrous sodium carbonate, shaken and filtered. The color of the solution turned pale yellow. Again the filtrate was added to with another $5 \mathrm{~g}$. portion of sodium carbonate and shaken. This time the color of the solution turned deep yellow. The filtrate was condenced to a syrup under reduced pressure $\left(20 \mathrm{~mm}\right.$. $\mathrm{Hg}$ ) below $37^{\circ} \mathrm{C}$. The brownish-colored syrup was allowed to stand in an ice box for 3-4 days whereby it changed into a crystalline mass. This was extracted with ether and the residue was treated with $20 \mathrm{ml}$. of hot ethylacetate and the ethyl acetate solution was cooled in an ice box for two or three days. Crystals formed in yellowish needles. After recrystallization from benzene the pure product was obtained. m.p. $107^{\circ} \mathrm{C} . \mathrm{N}, 5.4 \%$ (Calcd. $5.32 \%$ ). Yield, $0.75 \mathrm{~g}$. It was insoluble in ether and water, but soluble in acetone, methanol and ethanol.

Cleavage of 5,6-monoacetone- $\mathcal{N}-A c-D$-glucosaminol with lead tetraacetate. $300 \mathrm{mg}$. of 5,6-monoacetone-N-Ac-D-glucosaminol was suspended in 100 $\mathrm{ml}$. of anhydrous benzene, $40 \mathrm{~g}$. of lead tetraacetate were added in small portions under stirring and the mixture was shaken for 4-5 hours at room temperature. After completion of the oxidation (tested with iodine-starch reaction) the reaction mixture was filtered, and the filtrate was concentrated to a syrup in vacuo at $30^{\circ} \mathrm{C}$., and shaken with ether, and the residue was dissolved in $20 \mathrm{ml}$. of water. The solution gave strong Schiff's reaction. It was submitted immediately to further oxidation with bromine without isolating the aldehyde compounds by addition of bromine to $2 \%$ with following standing for $24 \mathrm{hrs}$. The solution gave no more Schiff's reaction. Then the excess of bromine was removed by aeration. The bromide ion was removed by the aid of an excess of silver acetate and silver ion by the aid of hydrogen sulfite. The filtrate was extransted with ethyl acetate and the ethyl acetate solution was concentrated in vacuo to a syrup, which crystallized on standing in an ice box. The product after recrystallization from ethanol melted at $207.6^{\circ} \mathrm{C}$. N, 9.2\% (Calcd. as N-Ac-serine, 9.52\%). $[\alpha]_{\mathrm{D}}^{22}$ (in water $)-2.05^{\circ}(\mathrm{c}=1)$. The yield was about 20 per cent of theory. Deacetylation of $\mathcal{N}$-acetyl-L-serine. $\mathrm{N}$-Ac-L-serine obtained was hydrolyzed by heating with $2 \mathcal{N}$ hydrochloric acid in a boiling water bath and free L-serine was obtained in crystalline form. m. p. $235.5^{\circ} \mathrm{C}$. (decomp.). $[\alpha]_{\mathrm{D}}^{\circ}$ (in $\left.1 \mathrm{~N} \mathrm{HCl}\right)+14.45^{\circ}$. These constants agree with those of L-serine. The product was also identified by paper chromatography.

\section{References}

1) Wolfrom, Lemieux \& Olin, J. Amer. Chem. Soc., 1949, 71, 2870. 
2) Zuckerkandl \& Messiner-Klebermass, Biochem. Z., 1931, 236, 19.

3) Karrer \& Meyer, Helv. Chim. Acta, 1937, 20, 626.

4) Nanji \& Paton, J. Chem. Soc., 1924, 125, 2474. 